\title{
Important Genes in the Pathogenesis of 5q-Syndrome and Their Connection with Ribosomal Stress and the Innate Immune System Pathway
}

\author{
Ota Fuchs $s^{1,2}$ \\ ${ }^{1}$ Institute of Hematology and Blood Transfusion, U Nemocnice 1, 12820 Prague 2, Czech Republic \\ ${ }^{2}$ Center of Experimental Hematology, First Medical Faculty, Charles University, Institute of Pathological Physiology, \\ 12853 Prague 2, Czech Republic
}

Correspondence should be addressed to Ota Fuchs, ota.fuchs@uhkt.cz

Received 25 September 2011; Revised 6 November 2011; Accepted 14 November 2011

Academic Editor: Daniela Cilloni

Copyright ( $) 2012$ Ota Fuchs. This is an open access article distributed under the Creative Commons Attribution License, which permits unrestricted use, distribution, and reproduction in any medium, provided the original work is properly cited.

\begin{abstract}
Myelodysplastic syndrome (MDS) with interstitial deletion of a segment of the long arm of chromosome 5q [del(5q)] is characterized by bone marrow erythroid hyperplasia, atypical megakaryocytes, thrombocythemia, refractory anemia, and low risk of progression to acute myeloid leukemia (AML) compared with other types of MDS. The long arm of chromosome 5 contains two distinct commonly deleted regions (CDRs). The more distal CDR lies in 5q33.1 and contains 40 protein-coding genes and genes coding microRNAs (miR-143, miR-145). In 5q-syndrome one allele is deleted that accounts for haploinsufficiency of these genes. The mechanism of erythroid failure appears to involve the decreased expression of the ribosomal protein S14 (RPS14) gene and the upregulation of the p53 pathway by ribosomal stress. Friend leukemia virus integration 1 (Fli1) is one of the target genes of miR145. Increased Flil expression enables effective megakaryopoiesis in 5q-syndrome.
\end{abstract}

\section{Introduction}

Approximately $15 \%$ of patients with MDS have abnormalities of chromosome 5 [1]. These abnormalities include interstitial deletion of a segment of the long arm of chromosome $5 q$ [del(5q), 5q-syndrome], monosomy, and unbalanced translocations. 5q-syndrome as MDS category was defined by the World Health Organization (WHO) [2], and it is characterized by refractory macrocytic anemia with dyserythropoiesis, transfusion dependence, normal to elevated platelet counts, hypolobated and nonlobated megakaryocytes, female preponderance, a favourable prognosis, and low risk of progression to AML compared with other types of MDS [3-10]. Many research groups analysed chromosome 5q deletions in patients with $5 \mathrm{q}$-syndrome. We will shortly describe these studies from historical point of view and not for relevance in the pathogenesis.

Deletion of interferon regulatory factor-1 gene (IRF1) mapped to chromosome $5 \mathrm{q} 31$ was detected [11]. IRF1 is a putative tumor suppressor and a transcriptional activator of interferon and interferon-stimulated genes. IRF1 dosage experiments demonstrated that 2 patients with $5 \mathrm{q}$-syndrome retained both copies of this gene [12]. Thus, IRF1 maps outside the common deleted segment of the $5 \mathrm{q}$-chromosome, and the same result was obtained in the case of EGR1 (epidermal growth receptor 1) $[13,14]$.

Molecular mapping techniques defined the region of gene loss in two patients with the $5 \mathrm{q}$-syndrome and uncharacteristically small 5q deletions (5q31-q33) [14]. The allelic loss of 10 genes localized to 5q23-qter [centromere-CSF2 (colony-stimulating factor 2/granulocyte-macrophage/)EGR1 (early growth response1)-FGFA (fibroblast growth factor acidic)-GRL (glucocorticoid receptor)-ADRB2 ( $\beta-2$ adrenergic receptor)-CSF1R (colony-stimulating factor 1 )SPARC (secreted protein, acidic, cysteine-rich/osteonectin/)GLUH1(human glutamate receptor 1)-NKSF1 (NK-cellstimulating factor chain 1)-FLT4 (Fms-related tyrosine kinase 4)-telomere] was investigated in peripheral blood cell 
fractions. Gene dosage experiments demonstrated that CSF2, EGR1, NKSF1, and FLT4 were retained on the $5 \mathrm{q}$-chromosome in both patients and that FGFA was retained in one patient, thus placing these genes outside the critical region. GRL, ADRB2, CSF1R, SPARC, and GLUH1 were shown to be deleted in both patients. The proximal breakpoint is localized between EGR1 and FGFA in one patient and between FGFA and ADRB2 in the other, and the distal breakpoint is localized between GLUH1 and NKSF1 in both patients [14]. Pulsed-field gel electrophoresis was used to map the 5q deletion breakpoints, and breakpointspecific fragments were detected with FGFA probe in the granulocyte but not the lymphocyte fraction of one patient. This study has established the critical region of gene loss of the $5 \mathrm{q}$-chromosome in the $5 \mathrm{q}$-syndrome, giving the location for a putative tumor-suppressor gene in the $5.6 \mathrm{Mb}$ region between FGFA and NKSF1 [14].

Boultwood et al. [15] characterised the commonly deleted region (CDR) in a study involving sixteen 5q-syndrome patients to a $1.5 \mathrm{Mb}$ interval located at $5 \mathrm{q} 32-5 \mathrm{q} 33$ between D5S413 marker and GLRA1 (glycine receptor subunit $\alpha-1$ ). This region contains PDE6A (phosphodiesterase 6A), CSF1R, CD74 (CD74/cluster of differentiation 74/molecule, major histocompatibility complex, class II invariant chain), TCOF1 (Treacher-Collins-Franceschetti syndrome 1), ANXA6 (annexin A6), SPARC, and FAT2 (FAT tummor suppressor hom$\operatorname{olog} 2$, also known as cadherin family member 8 or multiple epidermal growth factor-like domains protein 1) genes. Advanced MDS and AML had a large del(5q) which contained a distinct 5q31 CDR $[16,17]$.

It was shown that MDS arises from the transformation of a multipotent hematopoietic stem cell (HSC) or myeloidcommitted progenitor cell $[18,19]$. These data suggest that the gene or genes that are inactivated in the $5 \mathrm{q}$-syndrome will be expressed in normal hematopoietic stem and progenitor cells. The expression of all 40 genes assigned to the CDR by means of the Ensembl program was thus examined in normal human bone marrow $\mathrm{CD} 34^{+}$cells by means of RT-PCR. Of the 40 genes in the CDR, 33 were expressed in CD34 ${ }^{+}$ cells and, therefore, represented candidate genes since they were expressed within the HSC/progenitor cell compartment [15].

Cytogenetic mapping of commonly deleted regions (CDRs) centered on 5q31 and 5q32-5q33 identified candidate tumor-suppressor genes, including the transcription factor Egr1/Krox20 and the cytoskeletal remodeling protein, alpha-catenin on $5 \mathrm{q} 31$, and the ribosomal subunit protein RPS14 on $5 \mathrm{q} 32-5 \mathrm{q} 33$ (Figure 1). Although each acts as a tumor suppressor, alone or in combination, no molecular mechanism accounts for how defects in individual 5q candidates may act as a lesion driving MDS or contributing to malignant progression in MPN (myeloproliferative neoplasms). One candidate gene that resides between the conventional $\operatorname{del}(5 \mathrm{q}) / 5 \mathrm{q}-\mathrm{MDS}$-associated CDRs is DIAPH1 (5q31.3). DIAPH1 encodes the mammalian diaphanousrelated formin, mDial. mDial has critical roles in actin remodeling in cell division and in response to adhesive and migratory stimuli. Eisenmann et al. [20] examined evidence, with a focus on mouse gene-targeting experiments, that

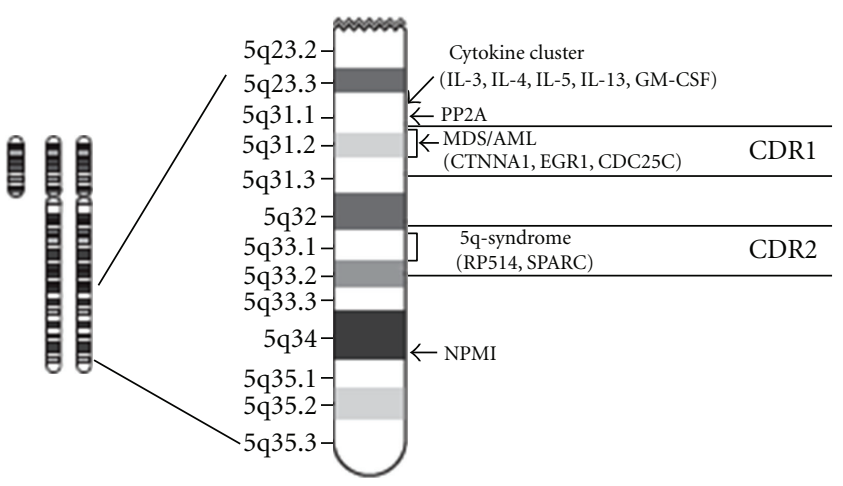

Figure 1: Schematic diagram of human chromosome $5 \mathrm{q}$ map showing commonly deleted regions.

mDial acts as a node in a tumor-suppressor network that involves multiple $5 \mathrm{q}$ gene products.

\section{The Possible Role of Candidate Genes from CDR in 5q-Syndrome}

All the 40 genes within the CDR were sequenced, and no mutations were found [21]. This finding suggests that $5 \mathrm{q}$-syndrome may be a "one-hit" cancer in contrast to the "two-hit hypothesis" for the mechanism of cancer development described by Knudson [22]. Knudson's two-hit model of tumour suppressor genes supposes that two mutations are required to cause a tumour, one occurring in each of the two alleles of the gene. Many reports described candidate tumour suppressors that do not conform to this standard definition, including haploinsufficient genes requiring inactivation of only one allele and genes inactivated not by mutation but rather epigenetic hypermethylation [23]. Thus, a dosage effect as the result of the loss of a single allele of a gene (haploinsufficiency) may be responsible for the $5 \mathrm{q}$-syndrome. Haploinsufficiency of multiple genes mapping to the CDR at 5q31-32 may contribute to the pathogenesis of 5q-syndrome [24-27]. Haploinsufficiency may be a driving force in cancer [28].

Boultwood et al. [21] compared the transcriptome of the $\mathrm{CD} 34^{+}$cells in a group of 10 patients with the $5 \mathrm{q}$-syndrome using the Affymetrix Gene Chip U133 Plus 2.0 array platform with the transcriptome of $\mathrm{CD} 34^{+}$cells from 16 healthy control subjects and 14 patients with refractory anemia and a normal karyotype. The majority of the genes assigned to the CDR of the $5 \mathrm{q}$-syndrome at $5 \mathrm{q} 31-\mathrm{q} 32$ showed a reduction in expression levels in patients with the 5q-syndrome, consistent with the loss of one allele. Candidate genes showing haploinsufficiency in the $5 \mathrm{q}$-syndrome included the tumour suppressor gene SPARC and RPS14, a component of the $40 S$ ribosomal subunit. Two genes mapping to the CDR, RBM22 (RNA-binding motif 22) and CSNK1A1 (casein kinase 1, $\alpha 1$ ), showed more than $50 \%$ reduction in gene expression, consistent with the downregulation of the remaining allele. RBM22 plays a role in splicing and nuclear translocation of the calcium binding protein ALG2 (apoptosis-linked gene 2) 
and causes deregulation of apoptosis [29]. CSNK1A1 regulates the Hedgehog signal pathway which governs cell growth in cooperation with Wnt signaling [30, 31]. This study identified several significantly deregulated gene pathways in patients with the $5 \mathrm{q}$-syndrome, and gene pathway analysis data supported the proposal that SPARC might play a role in the pathogenesis of the $5 \mathrm{q}$-syndrome.

2.1. Role of SPARC in 5q-Syndrome. Lehmann et al. [32] further studied the hematopoietic system in SPARC-null mice. These mice showed significantly lower platelet counts compared to wild-type animals. Although hemoglobin, hematocrit, and mean corpuscular volume (MCV) were lower in mice lacking SPARC, differences were not statistically significant. SPARC-null mice showed a significantly impaired ability to form erythroid burst-forming units (BFU-E). However, no significant differences were found in the formation of erythroid colony-forming units (CFU-E), granulocyte/monocyte colony-forming units (CFU-GM), or megakaryocyte colony-forming units (CFU-Mk) in these animals. These authors concluded that many of the genes within the CDR associated with the $5 \mathrm{q}$-syndrome exhibit significantly decreased expression and that SPARC, as a potential tumor suppressor gene, may play some but not the key role in the pathogenesis of this disease.

2.2. RPS14 and Ribosomopathies. Ebert et al. [33] used an RNA-mediated interference- (RNAi-) based approach to discovery of the $5 \mathrm{q}$ - disease gene. They found that partial loss of function of the ribosomal subunit protein RPS14 phenocopies the disease in normal haematopoietic progenitor cells. The forced expression of RPS14 with a lentiviral cDNA expression vector rescued the disease phenotype in patientderived bone marrow cells. In addition, they identified a block in the processing of preribosomal RNA in RPS14deficient cells. This block was functionally equivalent to the defect in Diamond-Blackfan anemia, linking the molecular pathophysiology of the 5q-syndrome to a congenital syndrome causing bone marrow failure [34]. These results indicate that the $5 \mathrm{q}$-syndrome is caused by a defect in ribosomal protein function and suggest that RNAi screening is an effective strategy for identifying causal haploinsufficiency disease genes. Multiple different RPS14 shRNAs decreased the ratio of erythroid to megakaryocytic cells produced in vitro. These RPS14 shRNAs decreased also the ratio of erythroid to myeloid cells and caused the apoptosis of differentiating erythroid cells. The decreased level of RPS14 gene expression in $5 \mathrm{q}$-syndrome is not caused by the aberrant methylation of the RPS14 gene promoter [35]. The 5q-syndrome belongs to ribosomopathies that are disorders in which genetic abnormalities cause impaired ribosome biogenesis and function [25].

Inherited mutations for several ribosomal protein genes (RPS19, RPS27A, RPS26, RPS24, RPS17, RPS15, RPS10, RPS7, RPL5, RPL11, RPL35a, and RPL36) cause DiamondBlackfan anemia (DBA, OMIM\#205900) [34, 36-46]. Josephs [47] and Diamond and Blackfan [48] reported the first cases of this rare disease almost exclusively affecting the erythroid lineage. DBA is characterized by a moderate to severe anemia with normal neutrophil and platelet counts and a marked reduction in number of red cell precursors in an otherwise normocellular bone marrow. Several other bone marrow failure syndromes are also associated with defects in ribosome biogenesis and function $[25,38]$.

A murine model of the human 5q-syndrome was developed in which haploinsufficiency of the Cd74-Nid67 (CD74 antigen gene-nerve growth factor-induced differentiation clone 67 gene) region containing the RPS14 gene on mouse chromosome 18 maps CDR of the human 5q-syndrome and contains 8 known genes [49]. This was achieved using CreloxP recombination to delete this region. An Lmo2-Cre transgene was used to restrict the deletion to the hematopoietic compartment. Two genes (Ndst1/glucosaminyl N-deacetylase/N-sulfotransferase 1 gene/and $C d 74$ ) from this segment on mouse chromosome 18 have been excluded as candidate genes. RPS14 was the major candidate gene in relation to the phenotype [49]. Mice with one deleted allele displayed hypocellular bone marrow as a consequence of a defect in hematopoietic progenitor function that could be rescued by p53 inactivation. This murine model also displayed a macrocytic anemia with dysplastic features in the bone marrow and monolobulated megakaryocytes, common features of $5 q$-syndrome. These changes correlated with an increase in a population of highly p53 positive cells in the bone marrow and with elevated apoptosis (see Section 4).

Pellagatti et al. [50] investigated the expression profiles of a large group of ribosomal- and translation-related genes in the $\mathrm{CD} 34^{+}$cells isolated from bone marrow samples of 15 MDS patients with $5 \mathrm{q}$-syndrome, 18 MDS patients with refractory anemia and a normal karyotype, and 17 healthy controls. Human genome U133 Plus 2.0 arrays (Affymetrix) covering over 47000 transcripts representing 39000 human genes were used in this study. The expression data for selected genes were validated using real-time quantitative PCR with predeveloped TaqMan assays (Applied Biosystems). The expression profiles of 579 probe sets for genes coding ribosomal proteins (229 for large $80 \mathrm{~S}$ ribosomal subunit/RPL/and 176 for small 40S ribosomal subunit/RPS/) and for genes coding translation-related factors (149 for eukaryotic translation initiation factors/EIF/and 25 for eukaryotic translation elongation factors/EEF/) were analysed [50]. 55 genes were differentially expressed. 49 from these 55 genes (89\%) showed lower expression in the $5 \mathrm{q}$-syndrome patient group in comparison with MDS patients with refractory anemia and a normal karyotype and in comparison with healthy controls. These data were compared with data about the defective expression of genes for ribosomal proteins and translation-related factors in DBA published by Pellagatti et al. [50]. Three genes (RPL28, RPS14, and EEF1D) expression was found downregulated in both diseases (MDS 5qsyndrome and DBA) [50, 51]. In addition, the expression of two pro-3poptotic genes, TNFRSF10B (tumor necrosis factor receptor superfamily, member $10 \mathrm{~b}$ gene) and BAX (BCL2associated $\mathrm{X}$ protein gene), was upregulated in both diseases. Pellagatti et al. [50] suggested that the deregulation observed in ribosomal gene expression and translation-related gene expression in the $\mathrm{CD} 34^{+}$cells isolated from bone marrow 

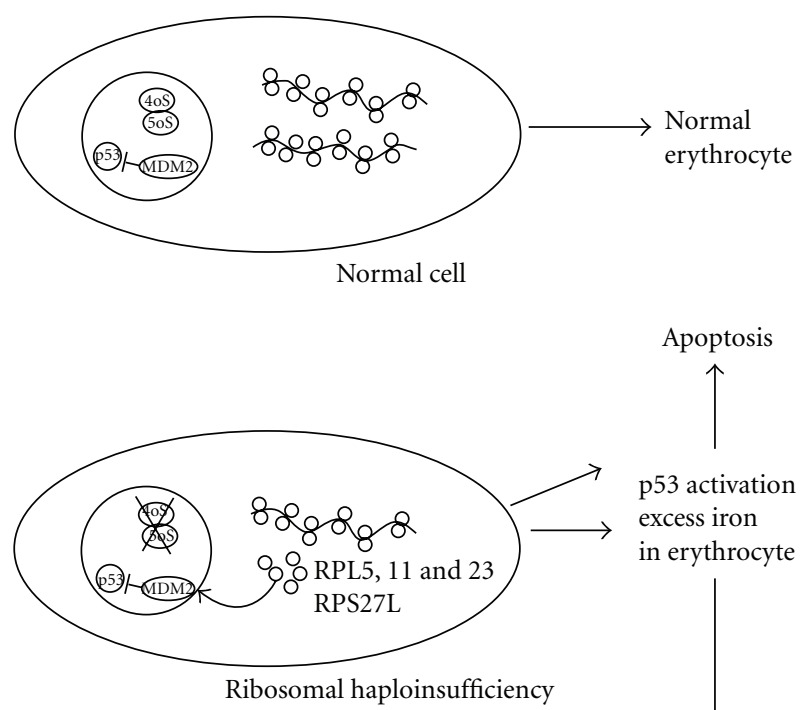

Apoptosis

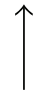

p53 activation

excess iron

in erythrocyte

Ribosomal haploinsufficiency adjacent to the distal boundary of the CDR and is also deleted in most patients with 5q-syndrome. Starczynowski et al. [59] identified Toll-interleukin-1 receptor domain-containing adaptor protein (TIRAP) and tumor necrosis factor receptorassociated factor-6 (TRAF6) as respective targets of these miRNAs. These miRNAs target corresponding genes through partial base pairing to the $3^{\prime}$-UTR of the target genes. These targets were aberrantly upregulated in 5q-syndrome [59]. Downregulation of the miRNAs (miR-145 and miR146a) led to an upregulation of IL-6 that was dependent on TRAF6. Elevated IL-6 was found also in patients with 5qsyndrome [60]. TIRAP is known to lie upstream of TRAF6 in innate immune signaling. Knockdown of miR-145 and miR146a together or enforced expression of TRAF6 in mouse HSPCs resulted in thrombocytosis, mild neutropenia, and megakaryocytic dysplasia. A subset of mice transplanted with TRAF6-expressing marrow progressed either to marrow failure or acute myeloid leukemia. Thus, inappropriate activation of innate immune signals in HSPCs phenocopies several clinical features of 5q-syndrome. Starczynowski et al. have recently showed that loss of two miRNAs, miR-145 and miR-146a, results in leukemia in a mouse model [61].

Patients with 5q-syndrome have decreased expression of miR-145 and increased expression of Fli-1 [62]. Overexpression of miR-145 or inhibition of Fli-1 in CD $34^{+}$cells decreases megakaryocyte production, while inhibition of miR-145 or overexpression of Fli-1 has the reciprocal effect. These findings have been validated in vivo using transgenic mice. Moreover, the combined loss of miR-145 and RPS14 cooperates to alter erythroid-megakaryocytic differentiation in a manner similar to the 5q-syndrome. Taken together, these findings demonstrated for the first time that coordinate deletion of a microRNA and a protein-coding gene (Figure 3 ) contributes to the phenotype of the 5q-syndrome [62].

Other research groups found normal expression levels of miR-145 in most CD34 ${ }^{+}$cells isolated from bone marrow samples of MDS patients with 5q-syndrome [63, 64]. Remarkably, the guardians of the genome p53, p73, and p63 play a role in control of most of the known tumor suppressor miRNAs $[65,66]$. Thus, it is possible that one allele of miR145 is lost in 5q-syndrome but the second allele of miR-145 is overexpressed after $\mathrm{p} 53$ or related genes activation. A putative tumor suppressing miRNA, miR-145, has been shown to be decreased in various human cancers $[67,68]$, and it decreases the apoptosis and proliferation rate of colorectal cancer cells and B-cell lymphoma cell lines [69, 70].

Zhang et al. [71] demonstrated that miR-145 targets a putative binding site in the $3^{\prime}$-UTR of the Friend leukemia virus integration 1 (Fli-1) gene and that miR-145 abundance is inversely related to Fli-1 expression in colon cancer tissues. Some other targets of miR-145 are important regulators of cell apoptosis and proliferation, such as c-Myc and IRS-1 $[62,72]$. IRS-1, a docking protein for both the type 1 insulinlike growth factor receptor and the insulin receptor, delivers antiapoptotic and antidifferentiation signals. MiR-145 also downregulates the protooncogene $\mathrm{c}-\mathrm{Myc}$, whose aberrant expression is associated with aggressive and poorly differentiated tumors. Zhang et al. [73] demonstrated that DNA fragmentation factor 45 (DFF45) expression is controlled at miR-145, and miR-146a. The miR-145 gene maps within the CDR of the $5 q$-syndrome [21], and the miR-146a gene lies 
the translational level by miR-145, using bioinformatic and proteomic techniques. DFF45 is caspase-3 or caspase-7 substrate that must be cleaved before apoptotic DNA fragmentation can proceed $[74,75]$.

Changes in the expression of miR-146a have been implicated in both the development of multiple cancers and in the negative regulation of inflammation induced via the innate immune response. Furthermore, miR-146a expression is driven by the transcription factor NF- $\kappa \mathrm{B}$ (nuclear factor kap$\mathrm{paB})$, which has been implicated as an important causal link between inflammation and carcinogenesis. Williams et al. [76] and $\mathrm{Li}$ et al. [77] reviewed the evidence for a role of miR-146a in innate immunity and cancer and assessed whether changes in miR-146a might link these two biological responses.

The role of miR-146a in hematopoiesis was investigated by using retroviral infection and overexpression of miR-146a in mouse hematopoietic stem/progenitor cells, followed by bone marrow transplantations [78]. miR-146a is mainly expressed in primitive hematopoietic stem cells and $\mathrm{T}$ lymphocytes. Overexpression of miR-146a in hematopoietic stem cells, followed by bone marrow transplantation, resulted in a transient myeloid expansion, decreased erythropoiesis, and impaired lymphopoiesis in select anatomical locations. Enforced expression of miR-146a also impaired bone marrow reconstitution in recipient mice and reduced survival of hematopoietic stem cells. These results indicate that miR-146a, a lipopolysaccharide- (LPS-) induced miRNA, regulates multiple aspects of hematopoietic differentiation and survival. Furthermore, the consequences of miR-146a expression in hematopoietic cells mimic some of the reported effects with acute LPS exposure.

Third gene for miRNA in the CDR is miR-143 [62]. Cordes et al. [79] and Boettger et al. [80] proposed that miR145 and miR-143 regulate smooth muscle cells (SMC) fate and plasticity and play the important role in cardiovascular development. MDS patients with 5q deletion were characterized by decreased levels of miR-143 and miR-378 mapped within the commonly deleted region at $5 \mathrm{q} 32$ [81].

\section{The Importance of p53 in the Molecular Mechanism of 5q-Syndrome}

Dysregulation of ribosome biogenesis through insufficiency of ribosomal subunits has been demonstrated to activate a p53 checkpoint and regulate developmental pathways [25, $82-86]$. The $\mathrm{p} 53$ pathway provides a surveillance mechanism for translation in protein synthesis and for genome integrity. The transcription factor p53 is encoded by TP53 tumor suppressor gene. Target genes of $\mathrm{p} 53$ regulate critical processes, such as apoptosis, cell cycle arrest, DNA repair, senescence, and cellular metabolism.

4.1. Activation of p53 by Ribosome Dysfunction in Model Systems. Activation of p53 stimulates proteasome-dependent truncation of eIF-4E-binding protein 1 (4E-BP1) [87]. The translational inhibitor protein 4E-BP1 regulates the availability of polypeptide chain initiation factor eIF4E for protein synthesis. Initiation factor eIF4E binds the $5^{\prime}$ cap structure present on all cellular mRNAs. Its ability to associate with initiation factors eIF4G and eIF4A, forming the eIF4F complex, brings the mRNA to the $43 \mathrm{~S}$ complex during the initiation of translation. Binding of eIF4E to eIF4G is inhibited in a competitive manner by $4 \mathrm{E}-\mathrm{BP} 1$. Phosphorylation of $4 \mathrm{E}-\mathrm{BP} 1$ decreases the affinity of this protein for eIF4E, thus favouring the binding of eIF4G and enhancing translation. The truncated protein $4 \mathrm{E}-\mathrm{BP} 1$ is almost completely unphosphorylated and exerts a long-term inhibitory effect on the availability of eIF4E, thus contributing to the inhibition of protein synthesis and the growth-inhibitory and proapoptotic effects of $\mathrm{p} 53$.

The murine double minute 2 protein (MDM2) and human analogue (HDM2) function as a link between ribosome biogenesis and the 53 pathway. MDM2 or HDM2 proteins function in two major ways: (1) as an E3 ubiquitin ligase that recognizes the $\mathrm{N}$-terminal transactivation domain (TAD) of the p53 tumor suppressor and (2) as an inhibitor of p53 transcriptional activation [88-90]. Having a short halflife, p53 is normally maintained at low levels in unstressed mammalian cells by continuous ubiquitination and subsequent degradation by the $26 \mathrm{~S}$ proteasome. This is primarily due to the interaction of p53 with the RING-finger ubiquitin E3 ligases, MDM2 or HDM2. MDM2 interacts with a variety of ribosomal proteins, including RPL5, RPL11, RPL23, RPL26, and RPS7 [91-99]. These interactions, which typically involve the acidic domain and sometimes the adjacent zinc finger of MDM2, interfere with the inhibitory functions of this region of MDM2 and contribute to p53 activation (Figure 2). As first exemplified for RPL11 [92], these interactions increase when ribosome biogenesis is disrupted, in a situation termed "ribosomal biogenesis stress" or "nucleolar stress" [100, 101]. Mechanistically, ribosomal stress causes translocation of free ribosomal proteins from the nucleolus to the nucleoplasm $[94,102]$, where they bind MDM2 [94]. The increased binding of ribosomal proteins to MDM2 augments cellular p53 activity, leading to growth arrest and coupling deficient protein synthesis with cessation of cell proliferation.

However, it is not clear whether ribosomal protein regulation of MDM2 is specific to some, but not all ribosomal proteins. Sun et al. [103] showed that RPL29 and RPL30, two ribosomal proteins from the $60 \mathrm{~S}$ ribosomal subunit, do not bind to MDM2 and do not inhibit MDM2-mediated p53 suppression, indicating that the ribosomal protein regulation of the MDM2-p53 feedback loop is specific.

4.2. Activation of p53 and Upregulation of the p53 Pathway in 5q-Syndrome. Results of several laboratories described in Section 4.1 showed that upregulation of the p53 pathway is a common response to haploinsufficiency of ribosomal proteins. Pellagatti et al. [104] carried out the analysis of the p53 pathway in the 5q-syndrome. They used Affymetrix arrays [50]. Ten genes in the p53 pathway (FAS/tumor necrosis factor receptor superfamily, member 6 gene/, CD82/cluster of differentiation 82 gene/, WIG1/wild type p53-induced gene 1 gene/, CASP3/cysteine-aspartic acid protease, caspase 3 


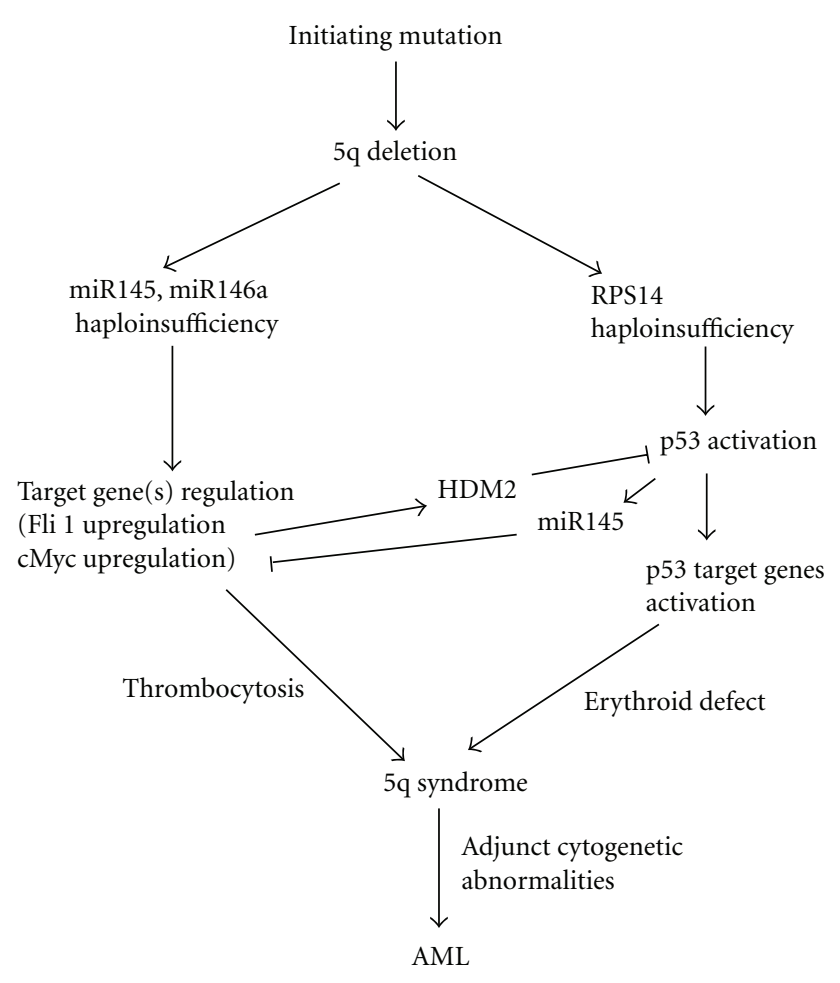

Figure 3: Schematic diagram of the development of the 5q-syndrome. The roles of the haploinsufficiency of RPS14, miR145, and miR146 and possible progression to AML by adjunct cytogenetic abnormalities are shown. Fli1 upregulation stimulates transcriptionally HDM2 [109] and inhibits partially p53 activation caused by ribosomal stress resulting from RPS14 haploinsufficiency.

gene/, SESN3/sestrin 3 gene/, TNFRSF10B, MDM4/murine double minute 4 gene/, $B A X, D D B 2 /$ damage-specific DNA binding protein 2 gene/, and BID2/BH3-interacting domain death agonist 2 gene/) were significantly deregulated. All these genes with exception of MDM4 (negative regulator of p53, structurally related to MDM2 [105]) were expressed at higher levels in $\mathrm{CD}_{3} 4^{+}$cells from $5 \mathrm{q}$-syndrome patients in comparison with healthy controls. MDM4 is expressed at lower level in 5q-syndrome patients. Further upregulated genes in 5q-syndrome ( $R P S 27 L /$ ribosomal protein S27-like gene/, PHLDA3/pleckstrin homology-like domain, family A, member 3 gene/, BCL11B/B-cell lymphoma/leukemia 11B gene/, and $F D X R /$ ferredoxin reductase gene/) are p53 targets $[21,50]$. Strong p53 expression was confirmed not only on the mRNA level but also on the protein level by an immunohistochemical analysis. Activation of p53 as a result of ribosomal stress seems to play an important role in the $5 q$-syndrome. Upregulation of the p53 pathway offers a new potential therapeutic target in the human $5 q$-syndrome. This therapy is possible only if the critical tumor suppressor function of p53 will be preserved.

4.3. The Relation between $p 53$ and miR145. The tumor suppressor p53 is a master gene regulator capable of regulating numerous genes. Since p53 plays a critical role in suppression of cell growth and proliferation, it is considered as a complementary opposite factor to the oncoprotein c-Myc. The oncoprotein c-Myc can counteract the p53's action to a great degree. The cell has developed sophisticated mechanisms during evolution to balance the effect of both these factors. It has been known for a long time that there is a negative correlation between p53 and c-Myc. Although previous report [106] suggested that this might involve transcriptional repression the precise mechanism of p53-mediated repression of c-Myc is not fully understood. Sachdeva et al. [107] have recently demonstrated that p53 induces $m i R-145$ and subsequently represses c-Myc. Thus, identification of $m i R-145$, that was described in Section 3 as a new player in this p53 regulatory network (Figure 3 ), provides at least one aspect of how the cell balances the effects of p53 and c-Myc [108].

4.4. TP53 Mutation in 5q-Syndrome. TP53 mutations were often detected in high-risk MDS and AML with $\operatorname{del}(5 q)$ [110, 111]. Jädersten et al. [112] described a patient with $5 \mathrm{q}$-syndrome with $\operatorname{del}(17 \mathrm{p})$ and TP53 mutation at disease progression. They demonstrated the TP53 mutant clone already at the initial diagnosis. Consequently, they analysed 55 patients with low- and int-1 risk MDS and $\operatorname{del}(5 \mathrm{q})$ and identified 10 patients (18\%) with TP53 mutations [113]. Moreover, they found a correlation between TP53 mutation and strong nuclear $\mathrm{p} 53$ protein expression in bone marrow progenitors [113]. Patients with mutations had significantly worse outcome. Clonal heterogeneity in low-risk 5qsyndrome patients may be of importance for the prognosis and therapy [113].

\section{Role of Further Genes in 5q-Syndrome}

5.1. The Role of Other Genes Positioned on $5 q$ Chromosome. The murine model for the 5q-syndrome with haploinsufficiency of the Cd74-Nid67 region described in the Section 2.2 showed that other gene in this region may play an additional role. Dctn4 gene encodes Dynactin 4, a subunit of the dynactin complex. The dynactin complex binds cargo, such as vesicles and organelles, to cytoplasmic dynein for retrograde microtubule-mediated trafficking [114]. Retroviral expression in megakaryocytes of dynamitin (p50), which disrupts dynactin-dynein function, inhibits proplatelet elongation [115]. Patel et al. [115] concluded that while continuous polymerization of microtubules is necessary to support the enlarging proplatelet mass, the sliding of overlapping microtubules is a vital component of proplatelet elongation. Thus, the inhibition of proplatelet elongation might reduce platelet formation and lead to thrombocytopenia [116]. The further gene Rbm22 was described in Section 2. RBM22 belongs to the SLT11 family; it has been reported to be involved in prespliceosome assembly and to interact with the $\mathrm{Ca}^{2+}$ signaling protein ALG-2 [117]. RBM22 is underexpressed in 5q-syndrome and deregulates probably apoptosis [29].

In addition to the minimal CDR on chromosome $5 q 33.1$ in 5q-syndrome, a second, proximal CDR on chromosome 5q31.2 contains genes EGR1, CTNNA1 (gene-encoding alpha-catenin), and HSPA9 (gene-encoding mortalin, GRP75, 
PBP74, and MTHSP75). Loss of this CDR contributes to a more aggressive MDS or AML phenotype $[16,17]$.

The gene for nucleophosmin (NPM1) localized on chromosome 5q35.1 (Figure 1) is deleted in many cases of 5q- MDS. Targeted knockout of one allele of NPM1 leads to genetic instability [118-120]. NPM1 heterozygous mice develop both myeloid and lymphoid malignancies. The bone marrow of these mice is hypercellular with evidence of dysplasia of the erythroid and megakaryocytic lineages. Immature erythroid cells accumulate in this bone marrow. The NPM1 haploinsufficiency in patients with large 5q deletions contributes to the phenotype of MDS. Moreover, NPM1 is the most commonly mutated gene in patients with normal karyotype AML [121-123].

5.2. The Role of Genes Not Positioned on Chromosome 5. We studied the role of the levels of mRNA for transcriptions factors Fli-1 (Friend leukemia virus integration 1) and EKLF (erythroid Krúppel-like factor, also named KLF1) in mononuclear cells isolated from bone marrow and peripheral blood of MDS patients with 5q-syndrome in comparison with patients with low risk MDS without $5 \mathrm{q}$ chromosome abnormality and with healthy controls [124, 125]. We found increased Flil mRNA levels and decreased EKLF mRNA levels in 5q-syndrome. The decreased expression of miR145 might be responsible for increased Fli-1 levels in 5qsyndrome (see Section 3 ). We suggest that increased Fli-1 expression in mononuclear cells of MDS patients with 5qsyndrome is further stimulated by the increased Fli-1 level and by the decreased EKLF level.

Fli-1 is a member of the Ets family of transcription factors. Fli-1 was originally identified as a protooncogene in Friend virus-induced erythroleukemia in mice [126]. The founding member of this family, the oncogene v-ets, was discovered in the genome of avian leukosis virus E26. Ets transcription factors bind to DNA elements containing the consensus sequence GGA(A/T). Fli-1 is preferentially expressed in hematopoietic cells and in vascular endothelial cells. Pulse-field gel analysis has localized the Fli-1gene within $240 \mathrm{~kb}$ of the Ets-1 locus on mouse chromosome 9 and on human chromosome 11q23, suggesting that these two ets genes arose by gene duplication from a common ancestral gene [127, 128]. Human Fli-1 contains nine exons which extend over approximately $120 \mathrm{~kb}$ [129].

Fli-1 plays an important role during the normal development of megakaryocytes. Fli-1 knockout mice produce small, undifferentiated megakaryocytic progenitors with abnormal features. Fli-1 represses the transcription of EKLF gene [130] and activates the promoters of several megakaryocyte-specific genes (glycoprotein IX and thrombopoietin receptor genes promoters) $[131,132]$. Fli-1 gene promoter is upregulated by Fli-1 and other Ets factors (Ets1, Ets2, and Elf1) but is inhibited by Tel [133]. Transcription factor PU.1 (also known as Spi-1) is also a positive regulator of the Fli1 gene [134]. On the other hand, PU.1 inhibits transcription factor GATA-1 function and erythroid differentiation by blocking GATA-1 DNA binding [135, 136]. Both, PU.1 and Fli-1 directly activate common target genes involved in ribosome biogenesis [137]. One of the consequences of miR145 and miR146a depletion or TIRAP and TRAF6 activation in the innate immune system pathway is overexpression of IL-6 which activates Fli-1 gene expression [59, 78, 138-140].

EKLF (erythroid Krúppel-like factor, also named KLF1) is a zinc finger transcription factor that plays a prominent role during erythroid development [141-143]. Human gene EKLF is positioned on chromosome 19p13.12-13 [144]. Commitment towards megakaryocyte versus erythroid blood cell lineages occurs in the megakaryocyte-erythroid progenitor (MEP). EKLF restricts megakaryocytic differentiation to the benefit of erythrocytic differentiation, and this effect is mediated by the inhibition of Fli- 1 recruitment to megakaryocytic and Fli-1 genes promoters [130, 145-147]. A marked increase in the number of circulating platelets in EKLF null mouse was found [148].

\section{Conclusions and Perspectives}

Candidate genes were studied using gene deletions or similar approaches to determine whether they have a role in 5qsyndrome, a subtype of MDS. A major advance occurred in 2008 when RNA interference-based approach for all 40 genes located within the $5 \mathrm{q}-$ CDR was used to discover the $5 \mathrm{q}$ disease gene. A defect in the function of a ribosomal protein RPS14 that is important for the proper processing of the 40S ribosomal subunit has been implicated in the pathophysiology of the 5q-syndrome. The RPS14 gene is located in the deleted region, and it seems that this loss affects erythroid differentiation. Haploinsufficiency of RPS14 gene in 5qsyndrome is associated with deregulation of ribosomal- and translation-related genes. Dutt et al. [149] found that p53 accumulates selectively in the erythroid lineage in primary human hematopoietic progenitor cells following expression of shRNAs targeting RPS14 or RPS19. Thus, 5q-syndrome is similarly as Diamond Blackfan anemia, where RPS 19 is the most commonly mutated gene, a ribosomopathy $[25,34,36$, $150,151]$.

Induction of $\mathrm{p} 53$ in both diseases, but not in control samples, led to lineage-specific accumulation of $\mathrm{p} 21^{W A F 1, C I P 1}$, also known as cyclin-dependent kinase inhibitor 1 or CDKinteracting protein 1 (a proliferation arrest determinating protein that in humans is encoded by the CDKN1A gene located on chromosome 6p21.2). The induction of p21 $1^{W A F 1, C I P 1}$ caused cell cycle arrest in erythroid progenitor cells. Pharmacological inhibition of p53 rescued the erythroid defect, while a compound that activates p53 through inhibition of HDM2, nutlin-3, selectively impaired erythropoiesis [149]. The increased apoptosis was observed in the 5q- mouse bone marrow [35]. In response to diverse stresses, the tumor suppressor p53 differently regulates its target genes, inducing cell cycle arrest, apoptosis, or senescence. The p53 is critical regulator of hematopoietic stem cell (HSC) behavior and plays an important role in regulating HSC quiescence, self-renewal, apoptosis, and aging. The p53 promotes HSC quiescence $[152,153]$. The mutant p53 protein can provide escape from apoptosis and facilitates also the entry of HSC to the cell cycle. Mutations in TP53 are 
relatively uncommon in cases of primary (de novo) MDS but have high incidence in patients with therapy-related MDS [154-156]. Garderet et al. [157] found defective erythroid proliferation but not differentiation capacity related to RPS14 gene haploinsufficiency. They used in vitro model of erythropoiesis $[158,159]$ in which mature red blood cells are generated from human progenitor cells to analyze cell proliferation and differentiation in a homogeneous erythroid population with RPS14 gene haploinsufficiency in culture. The enucleation capacity of $5 \mathrm{q}$ - clones remained unchanged. Therefore, the decreased erythroid maturation and subsequent anemia seen in 5q-syndrome are unlikely caused by a specific blockade of late differentiation and are probably the consequences of the proliferative defect of both pathological and residual nondeleted clones in the patient's bone marrow [160].

Treatment of zebrafish models of ribosomopathies with L-leucine results in an improvement of anemia and developmental defects in both diseases (Diamond Blackfan anemia and 5q-syndrome) [161]. Cmejlova et al. [162] demonstrated that the efficiency of mRNA translation is significantly depressed in cells derived from Diamond Blackfan anemia patients, consistent with a pathogenic ribosomal defect. L-leucine is an essential branched chain amino acid that is known to modulate protein synthesis by enhancing translation [162-166]. L-leucine has been used to treat Diamond Blackfan anemia patients [162, 167]. Treatment of RPS19, and RPS14-deficient zebrafish embryos and human hematopoietic progenitor $\mathrm{CD} 34^{+}$cells with L-leucine resulted in partial reversal of both the anemia and the developmental defects and provided evidence for a common signaling pathway involving the mTOR (mammalian target of rapamycin) integrating growth-promoting and stress signals [161].

From a translational point of view, the identification of the genes and miRNAs involved in the pathogenesis of the $5 q$-syndrome may support the development of novel targeted therapeutic strategies. The immunomodulatory drug lenalidomide (CC-5013; REVLIMID, Celgene Corporation), a structural analogue of thalidomide, is indicated for the treatment of the $5 \mathrm{q}$-syndrome MDS patients, rendering $67 \%$ of patients transfusion independent and inducing cytogenetic responses in over $40 \%$ of them [168-173]. In contrast, in a large multicenter trial involving transfusion: dependent MDS patients without $\operatorname{del}(5 q)$ only $26 \%$ achieved transfusion independence with infrequent cytogenetic improvement [174]. The selective and specific activity of lenalidomide in MDS remains undefined. Gene expression profiling and disease- and therapy-associated proteome changes in the sera of MDS patients were used for monitoring and predicting the response to therapy $[175,176]$. Wei et al. [177] provided evidence that lenalidomide is selectively cytotoxic to del(5q) cells as a result of inhibition of the haplodeficient dual specificity phosphatases, Cdc25C and PP2A. Phosphorylation of MDM2 and Fli-1 is important for the level and the activity of both these proteins involved in the process of erythroid failure in 5q-syndrome, and the level of PP2A regulates accumulation and degradation of p53 and Fli-1 $[178,179]$. The mechanism of action of lenalidomide is complex and includes inhibition of a wide array of proinflammatory cytokines, such as interleukin-6 (IL-6), and upregulation of T-helper-secreted cytokines, such as IL-2 and IFN-gamma [180]. It has been also described that IL2 subsequently activates natural killer (NK) cells. In view of the recently revealed role of IL- 6 in the pathogenesis of the $5 q$-syndrome $[59,138]$, it is tempting to speculate that the responses induced by lenalidomide therapy in patients with this disorder are due to downregulation of IL-6. Therefore, IL-6 expression and/or upstream regulators, such as TRAF6, may represent targets, which suggests that agents capable of inhibiting the TRAF6-IL-6 axis may be clinically useful for the management of $5 q$-syndrome $[59,138]$.

Lenalidomide inhibits the malignant clone and upregulates the SPARC and RPS14 genes expression [181, 182]. Both these genes are localized in CDR on chromosome 5. Induction of miR-143 and miR-145 in CD $34^{+}$cells of MDS patients with the $\operatorname{del}(5 q)$ abnormality after exposure to lenalidomide correlates with clinical response [179]. The beneficial effect of lenalidomide in patients with $5 \mathrm{q}$-syndrome is associated with significant increases in the proportion of bone marrow erythroid precursor cells and in the frequency of clonogenic progenitor cells, a substantial improvement in the hematopoiesis-supporting potential of bone marrow stroma and significant alterations in the adhesion profile of bone marrow $\mathrm{CD}^{+} 4^{+}$cells [183]. Although lenalidomide efficiently reduced a larger fraction of the $\operatorname{del}(5 q)$ stem cells, some rare and phenotypically distinct quiescent $\operatorname{del}(5 \mathrm{q})$ stem cells remained resistant to lenalidomide $[112,184]$. Over time, lenalidomide resistance developed in most of the patients with recurrence or expansion of the $\operatorname{del}(5 q)$ clone and clinical and cytogenetic progression. The resistant clone, insensitive to lenalidomide, overexpresses p53 and sequencing confirmed TP53 mutation [185]. The presence of easily detectable subclones with inactivated p53, and thereby a more malignant potential, is important and has prognostic value.

\section{Acknowledgments}

This work was supported by the research intention VZ 00023736 from the Ministry of Health of the Czech Republic, Grant MSM 0021620808 and Grant LC 06044 from Ministry of Education, Youth and Sport of the Czech Republic.

\section{References}

[1] D. Haase, U. Germing, J. Schanz et al., "New insights into the prognostic impact of the karyotype in MDS and correlation with subtypes: evidence from a core dataset of 2124 patients," Blood, vol. 110, no. 13, pp. 4385-4395, 2007.

[2] R. P. Hasserjian, M. M. Le Beau, A. F. List et al., WHO Classification of Tumors of Haematopoietic and Lymphoid Tissues, International Agency for Research on Cancer Press, Lyon, France, 2007.

[3] H. Van Den Berghe, J. J. Cassiman, and G. David, "Distinct haematological disorder with deletion of long arm of No. 5 chromosome," Nature, vol. 251, no. 5474, pp. 437-438, 1974. 
[4] H. Van Den Berghe, K. Vermaelen, and C. Mecucci, "The 5qanomaly," Cancer Genetics and Cytogenetics, vol. 17, no. 3, pp. 189-255, 1985.

[5] S. D. Nimer and D. W. Golde, "The 5q-abnormality," Blood, vol. 70, no. 6, pp. 1705-1712, 1987.

[6] P. Mathew, A. Tefferi, G. W. Dewald et al., "The 5q- syndrome: a single-institution study of 43 consecutive patients," Blood, vol. 81, no. 4, pp. 1040-1045, 1993.

[7] J. Boultwood, S. Lewis, and J. S. Wainscoat, "The 5qsyndrome," Blood, vol. 84, no. 10, pp. 3253-3260, 1994.

[8] H. Van Den Berghe and L. Michaux, "5q-, twenty-five years later: a synopsis," Cancer Genetics and Cytogenetics, vol. 94, no. 1, pp. 1-7, 1997.

[9] A. A. N. Giagounidis, U. Germing, J. S. Wainscoat, J. Boultwood, and C. Aul, "The 5q-syndrome," Hematology, vol. 9, no. 4, pp. 271-277, 2004.

[10] A. Mohamedali and G. J. Mufti, "Van-den Berghe's 5qsyndrome in 2008," British Journal of Haematology, vol. 144, no. 2, pp. 157-168, 2009.

[11] C. L. Willman, C. E. Sever, M. G. Pallavicini et al., "Deletion of IRF-1, mapping to chromosome 5q31.1, in human leukemia and preleukemic myelodysplasia," Science, vol. 259, no. 5097, pp. 968-971, 1993.

[12] J. Boultwood, C. Fidler, S. Lewis et al., "Allelic loss of IRF1 in myelodysplasia and acute myeloid leukemia: retention of IRF1 on the 5q- chromosome in some patients with the 5qsyndrome," Blood, vol. 82, no. 9, pp. 2611-2616, 1993.

[13] M. M. Le Beau, R. Espinosa, W. L. Neuman et al., "Cytogenetic and molecular delineation of the smallest commonly deleted region of chromosome 5 in malignant myeloid diseases," Proceedings of the National Academy of Sciences of the United States of America, vol. 90, no. 12, pp. 5484-5488, 1993.

[14] J. Boultwood, C. Fidler, S. Lewis et al., "Molecular mapping of uncharacteristically small $5 \mathrm{q}$ deletions in two patients with the $5 q$ - syndrome: delineation of the critical region on $5 q$ and identification of a 5q- breakpoint," Genomics, vol. 19, no. 3, pp. 425-432, 1994.

[15] J. Boultwood, C. Fidler, A. J. Strickson et al., "Narrowing and genomic annotation of the commonly deleted region of the 5q- syndrome," Blood, vol. 99, no. 12, pp. 4638-4641, 2002.

[16] R. J. Jaju, J. Boultwood, F. J. Oliveret et al., "Molecular cytogenc definition of the critical deleted region in the $5 \mathrm{q}$ syndrome," Genes Chromosomes Cancer, vol. 22, pp. 251-256, 1998.

[17] N. Zhao, A. Stoffel, P. W. Wang et al., "Molecular delineation of the smallest commonly deleted region of chromosome 5 in malignant myeloid diseases to $1-1.5 \mathrm{Mb}$ and preparation of a PAC-based physical map," Proceedings of the National Academy of Sciences of the United States of America, vol. 94, no. 13, pp. 6948-6953, 1997.

[18] M. L. Heaney and D. W. Golde, "Myelodysplasia," The New England Journal of Medicine, vol. 340, no. 21, pp. 1649-1660, 1999.

[19] L. Nilsson, I. Astrand-Grundstrom, I. Arvidsson et al., "Isolation and characterization of hematopoietic progenitor/stem cells in 5q-deleted myelodysplastic syndromes: evidence for involvement at the hematopoietic stem cell level," Blood, vol. 96, no. 6, pp. 2012-2021, 2000.

[20] K. M. Eisenmann, K. J. Dykema, S. F. Matheson et al., “5qmyelodysplastic syndromes: chromosome $5 \mathrm{q}$ genes direct a tumor-suppression network sensing actin dynamics," Oncogene, vol. 28, no. 39, pp. 3429-3441, 2009.
[21] J. Boultwood, A. Pellagatti, H. Cattan et al., "Gene expression profiling of CD34+ cells in patients with the 5q- syndrome," British Journal of Haematology, vol. 139, no. 4, pp. 578-589, 2007.

[22] A. G. Knudson, "Mutation and cancer: statistical study of retinoblastoma," Proceedings of the National Academy of Sciences of the United States of America, vol. 68, no. 4, pp. 820823, 1971.

[23] A. J. W. Paige, "Redefining tumour suppressor genes: exceptions to the two-hit hypothesis," Cellular and Molecular Life Sciences, vol. 60, no. 10, pp. 2147-2163, 2003.

[24] B. L. Ebert, "Deletion 5q in myelodysplastic syndrome: a paradigm for the study of hemizygous deletions in cancer," Leukemia, vol. 23, no. 7, pp. 1252-1256, 2009.

[25] A. Narla and B. L. Ebert, "Ribosomopathies: human disorders of ribosome dysfunction," Blood, vol. 115, no. 16, pp. 3196-3205, 2010.

[26] M. Tormo, I. Marugán, and M. Calabuig, "Myelodysplastic syndromes: an update on molecular pathology," Clinical and Translational Oncology, vol. 12, no. 10, pp. 652-661, 2010.

[27] M. S. Davids and D. P. Steensma, "The molecular pathogenesis of myelodysplastic syndromes," Cancer Biology and Therapy, vol. 10, no. 4, pp. 309-319, 2010.

[28] A. H. Berger and P. P. Pandolfi, "Haplo-insufficiency: a driving force in cancer," Journal of Pathology, vol. 223, no. 2, pp. 137-146, 2011.

[29] P. Montaville, Y. Dai, C. Y. Cheung et al., "Nuclear translocation of the calcium-binding protein ALG-2 induced by the RNA-binding protein RBM22," Biochimica et Biophysica Acta, vol. 1763, no. 11, pp. 1335-1343, 2006.

[30] J. Jia, C. Tong, B. Wang, L. Luo, and J. Jiang, "Hedgehog signalling activity of smoothened requires phosphorylation by protein kinase A and casein kinase I," Nature, vol. 432, no. 7020, pp. 1045-1050, 2004.

[31] A. Hämmerlein, J. Weiske, and O. Huber, "A second protein kinase CK1-mediated step negatively regulates Wnt signalling by disrupting the lymphocyte enhancer factor- $1 / \beta$ catenin complex," Cellular and Molecular Life Sciences, vol. 62, no. 5, pp. 606-618, 2005.

[32] S. Lehmann, J. O’Kelly, S. Raynaud, S. E. Funk, E. H. Sage, and H. P. Koeffler, "Common deleted genes in the 5qsyndrome: thrombocytopenia and reduced erythroid colony formation in SPARC null mice," Leukemia, vol. 21, no. 9, pp. 1931-1936, 2007.

[33] B. L. Ebert, J. Pretz, J. Bosco et al., "Identification of RPS14 as a $5 \mathrm{q}$ - syndrome gene by RNA interference screen," Nature, vol. 451, no. 7176, pp. 335-339, 2008.

[34] S. R. Ellis and P. E. Gleizes, "Diamond Blackfan anemia: ribosomal proteins going rogue," Seminars in Hematology, vol. 48, pp. 89-96, 2011.

[35] A. Valencia, J. Cervera, E. Such, M. A. Sanz, and G. F. Sanz, "Lack of RPS14 promoter aberrant methylation supports the haploinsufficiency model for the 5q-Syndrome," Blood, vol. 112, no. 3, p. 918, 2008.

[36] N. Draptchinskaia, P. Gustavsson, B. Andersson et al., "The gene encoding ribosomal protein S19 is mutated in Diamond-Blackfan anaemia," Nature Genetics, vol. 21, no. 2, pp. 169-175, 1999.

[37] H. T. Gazda, A. Grabowska, L. B. Merida-Long et al., "Ribosomal protein S24 gene is mutated in Diamond-Blackfan anemia," American Journal of Human Genetics, vol. 79, no. 6, pp. 1110-1118, 2006. 
[38] K. A. Ganapathi and A. Shimamura, "Ribosomal dysfunction and inherited marrow failure," British Journal of Haematology, vol. 141, no. 3, pp. 376-387, 2008.

[39] M. F. Campagnoli, U. Ramenghi, M. Armiraglio et al., "RPS19 mutations in patients with Diamond-Blackfan anemia," Human Mutation, vol. 29, no. 7, pp. 911-920, 2008.

[40] R. Cmejla, J. Cmejlova, H. Handrkova et al., "Identification of mutations in the ribosomal protein L5 (RPL5) and ribosomal protein L11 (RPL11) genes in Czech patients with diamond-blackfan anemia," Human Mutation, vol. 30, no. 3, pp. 321-327, 2009.

[41] J. M. Lipton and S. R. Ellis, "Diamond-blackfan anemia: diagnosis, treatment, and molecular pathogenesis," Hematology/Oncology Clinics of North America, vol. 23, no. 2, pp. 261282, 2009.

[42] L. Doherty, M. R. Sheen, A. Vlachos et al., "Ribosomal protein genes RPS10 and RPS26 are commonly mutated in diamond-blackfan anemia," American Journal of Human Genetics, vol. 86, no. 2, pp. 222-228, 2010.

[43] E. E. Devlin, L. DaCosta, N. Mohandas, G. Elliott, and D. M. Bodine, "A transgenic mouse model demonstrates a dominant negative effect of a point mutation in the RPS19 gene associated with Diamond-Blackfan anemia," Blood, vol. 116 , no. 15 , pp. 2826-2835, 2010.

[44] J. Hoefele, A. M. Bertrand, M. Stehr et al., "Disorders of sex development and Diamond-Blackfan anemia: is there an association?" Pediatric Nephrology, vol. 25, no. 7, pp. 12551261, 2010.

[45] E. Ito, Y. Konno, T. Toki, and K. Terui, "Molecular pathogenesis in Diamond-Blackfan anemia," International Journal of Hematology, vol. 92, no. 3, pp. 413-418, 2010.

[46] I. Boria, E. Garelli, H. T. Gazda et al., "The ribosomal basis of diamond-blackfan anemia: mutation and database update," Human Mutation, vol. 31, no. 12, pp. 1269-1279, 2010.

[47] H. W. Josephs, "Anemia of infancy and early childhood," Medicine, vol. 15, pp. 307-451, 1936.

[48] L. K. Diamond and K. D. Blackfan, "Hypoplastic anemia," Am. J. Dis. Child., vol. 56, pp. 464-467, 1938.

[49] J. L. Barlow, L. F. Drynan, D. R. Hewett et al., "A p53dependent mechanism underlies macrocytic anemia in a mouse model of human 5q-syndrome," Nature Medicine, vol. 16, no. 1, pp. 59-66, 2010.

[50] A. Pellagatti, E. Hellström-Lindberg, A. Giagounidis et al., "Haploinsufficiency of RPS14 in 5q- syndrome is associated with deregulation of ribosomal- and translation-related genes," British Journal of Haematology, vol. 142, no. 1, pp. 5764, 2008.

[51] H. T. Gazda, A. T. Kho, D. Sanoudou et al., "Defective ribosomal protein gene expression alters transcription, translation, apoptosis, and oncogenic pathways in Diamond-Blackfan anemia," Stem Cells, vol. 24, no. 9, pp. 2034-2044, 2006.

[52] K. Sridhar, D. T. Ross, R. Tibshirani, A. J. Butte, and P. L. Greenberg, "Relationship of differential gene expression profiles in CD34+ myelodysplastic syndrome marrow cells to disease subtype and progression," Blood, vol. 114, no. 23, pp. 4847-4858, 2009.

[53] H. He and Y. Sun, "Ribosomal protein S27L is a direct p53 target that regulates apoptosis," Oncogene, vol. 26, no. 19, pp. 2707-2716, 2007.

[54] J. Li, J. Tan, L. Zhuang et al., "Ribosomal protein S27-like, a p53-inducible modulator of cell fate in response to genotoxic stress," Cancer Research, vol. 67, no. 23, pp. 11317-11326, 2007.
[55] M. J. Farquhar and D. T. Bowen, "Oxidative stress and the myelodysplastic syndromes," International Journal of Hematology, vol. 77, no. 4, pp. 342-350, 2003.

[56] H. Ghoti, J. Amer, A. Winder, E. Rachmilewitz, and E. Fibach, "Oxidative stress in red blood cells, platelets and polymorphonuclear leukocytes from patients with myelodysplastic syndrome," European Journal of Haematology, vol. 79, no. 6, pp. 463-467, 2007.

[57] B. Novotna, Y. Bagryantseva, M. Siskova, and R. Neuwirtova, "Oxidative DNA damage in bone marrow cells of patients with low-risk myelodysplastic syndrome," Leukemia Research, vol. 33, no. 2, pp. 340-343, 2009.

[58] D. P. Bartel, "MicroRNAs: target recognition and regulatory functions," Cell, vol. 136, no. 2, pp. 215-233, 2009.

[59] D. T. Starczynowski, F. Kuchenbauer, B. Argiropoulos et al., "Identification of miR-145 and miR-146a as mediators of the 5q-syndrome phenotype," Nature Medicine, vol. 16, no. 1, pp. 49-58, 2010.

[60] E. Terpos, E. Verrou, A. Banti, V. Kaloutsi, A. Lazaridou, and K. Zervas, "Bortezomib is an effective agent for MDS/MPD syndrome with 5q- anomaly and thrombocytosis," Leukemia Research, vol. 31, no. 4, pp. 559-562, 2007.

[61] D. T. Starczynowski, R. Morin, A. McPherson et al., "Genome-wide identification of human microRNAs located in leukemia-associated genomic alterations," Blood, vol. 117, pp. 595-607, 2011.

[62] M. Kumar, A. Narla, A. Nonami et al., "Coordinate loss of a microRNA and protein-coding gene cooperate in the pathogenesis of 5q- syndrome," Blood, vol. 118, pp. 46634673, 2011.

[63] J. Boultwood, A. Pellagatti, A. N. J. McKenzie, and J. S. Wainscoat, "Advances in the 5q-syndrome," Blood, vol. 116, no. 26, pp. 5803-5811, 2010.

[64] H. Votavova, M. Grmanova, M. Dostalova Merkerova et al., "Differential expression of microRNAs in CD34+ cells of 5qsyndrome," Journal of Hematology and Oncology, vol. 4, p. 1, 2011.

[65] H. I. Suzuki, K. Yamagata, K. Sugimoto, T. Iwamoto, S. Kato, and K. Miyazono, "Modulation of microRNA processing by p53," Nature, vol. 460, no. 7254, pp. 529-533, 2009.

[66] L. Boominathan, "The guardians of the genome ( $\mathrm{p} 53$, TA-p73, and TA-p63) are regulators of tumor suppressor miRNAs network," Cancer and Metastasis Reviews, vol. 29, no. 4, pp. 613-639, 2010.

[67] M. Ozen, C. J. Creighton, M. Ozdemir, and M. Ittmann, "Widespread deregulation of microRNA expression in human prostate cancer," Oncogene, vol. 27, no. 12, pp. 17881793, 2008.

[68] Y. Wang and C. G. L. Lee, "MicroRNA and cancer-focus on apoptosis," Journal of Cellular and Molecular Medicine, vol. 13, no. 1, pp. 12-23, 2009.

[69] Y. Akao, Y. Nakagawa, and T. Naoe, "MicroRNA-143 and 145 in colon cancer," DNA and Cell Biology, vol. 26, no. 5, pp. 311-320, 2007.

[70] M. Sachdeva and Y. Y. Mo, "miR-145-mediated suppression of cell growth, invasion and metastasis," American Journal of Translational Research, vol. 2, no. 2, pp. 170-180, 2010.

[71] J. Zhang, H. Guo, H. Zhang et al., "Putative tumor suppressor miR-145 inhibits colon cancer cell growth by targeting oncogene friend leukemia virus integration 1 gene," Cancer, vol. 117, no. 1, pp. 86-95, 2011. 
[72] B. Shi, L. Sepp-Lorenzino, M. Prisco, P. Linsley, T. Deangelis, and R. Baserga, "Micro RNA 145 targets the insulin receptor substrate-1 and inhibits the growth of colon cancer cells," Journal of Biological Chemistry, vol. 282, no. 45, pp. 32582 32590, 2007.

[73] J. Zhang, H. Guo, G. Qian et al., "MiR-145, a new regulator of the DNA Fragmentation Factor-45 (DFF45)-mediated apoptotic network," Molecular Cancer, vol. 9, article 211, 2010.

[74] C. C. Chiu, C. H. M. Y. Lin, and K. Fang, "Etoposide (VP-16) sensitizes p53-deficient human non-small cell lung cancer cells to caspase-7-mediated apoptosis," Apoptosis, vol. 10, no. 3, pp. 643-650, 2005.

[75] X. Liu, H. Zou, C. Slaughter, and X. Wang, "DFF, a heterodimeric protein that functions downstream of caspase3 to trigger DNA fragmentation during apoptosis," Cell, vol. 89, no. 2, pp. 175-184, 1997.

[76] A. E. Williams, M. M. Perry, S. A. Moschos, H. M. LarnerSvensson, and M. A. Lindsay, "Role of miRNA-146a in the regulation of the innate immune response and cancer," Biochemical Society Transactions, vol. 36, no. 6, pp. 1211-1215, 2008.

[77] L. Li, X.-P. Chen, and Y.-J. Li, "MicroRNA-146a and human disease," Scandinavian Journal of Immunology, vol. 71, pp. 227-231, 2010.

[78] D. T. Starczynowski, F. Kuchenbauer, and J. Wegrzyn, "MicroRNA-146a disrupts hematopoietic differentiation and survival," Experimental Hematology, vol. 39, pp. 167-178, 2011.

[79] K. R. Cordes, N. T. Sheehy, M. P. White et al., "MiR-145 and miR-143 regulate smooth muscle cell fate and plasticity," Nature, vol. 460, no. 7256, pp. 705-710, 2009.

[80] T. Boettger, N. Beetz, S. Kostin et al., "Acquisition of the contractile phenotype by murine arterial smooth muscle cells depends on the Mir143/145 gene cluster," Journal of Clinical Investigation, vol. 119, no. 9, pp. 2634-2647, 2009.

[81] M. Dostalova Merkerova, Z. Krejcik, H. Votavova, M. Belickova, A. Vasikova, and J. Cermak, "Distinctive microRNA expression profiles in CD34+ bone marrow cells from patients with myelodysplastic syndrome," European Journal of Human Genetics, vol. 19, pp. 313-319, 2011.

[82] L. Panić, J. Montagne, M. Cokarić, and S. Volarević, "S6haploinsufficiency activates the p53 tumor suppressor," Cell Cycle, vol. 6, no. 1, pp. 20-24, 2007.

[83] N. Danilova, K. M. Sakamoto, and S. Lin, "Ribosomal protein S19 deficiency in zebrafish leads to developmental abnormalities and defective erythropoiesis through activation of p53 protein family," Blood, vol. 112, no. 13, pp. 5228-5237, 2008.

[84] N. C. Jones, M. L. Lynn, K. Gaudenz et al., "Prevention of the neurocristopathy Treacher Collins syndrome through inhibition of p53 function," Nature Medicine, vol. 14, no. 2, pp. 125-133, 2008.

[85] K. A. McGowan, J. Z. Li, C. Y. Park et al., "Ribosomal mutations cause p53-mediated dark skin and pleiotropic effects," Nature Genetics, vol. 40, no. 8, pp. 963-970, 2008.

[86] M. Barkić, S. Crnomarković, K. Grabušić et al., "The p53 tumor suppressor causes congenital malformations in Rpl24deficient mice and promotes their survival," Molecular and Cellular Biology, vol. 29, no. 10, pp. 2489-2504, 2009.

[87] C. Constantinou, A. Elia, and M. J. Clemens, "Activation of p53 stimulates proteasome-dependent truncation of elF4Ebinding protein 1 (4E-BP1)," Biology of the Cell, vol. 100, no. 5, pp. 279-289, 2008.
[88] J. Momand, H. H. Wu, and G. Dasgupta, "MDM2-master regulator of the p53 tumor suppressor protein," Gene, vol. 242, no. 1-2, pp. 15-29, 2000.

[89] S. Fang, J. P. Jensen, R. L. Ludwig, K. H. Vousden, and A. $\mathrm{M}$. Weissman, "Mdm2 is a RING finger-dependent ubiquitin protein ligase for itself and p53," Journal of Biological Chemistry, vol. 275, no. 12, pp. 8945-8951, 2000.

[90] H. V. Clegg, K. Itahana, and Y. Zhang, "Unlocking the Mdm2-p53 loop: ubiquitin is the key," Cell Cycle, vol. 7, no. 3, pp. 287-292, 2008.

[91] M. S. Dai and H. Lu, "Inhibition of MDM2-mediated p53 ubiquitination and degradation by ribosomal protein L5," Journal of Biological Chemistry, vol. 279, no. 43, pp. 4447544482, 2004.

[92] M. A. E. Lohrum, R. L. Ludwig, M. H. G. Kubbutat, M. Hanlon, and K. H. Vousden, "Regulation of HDM2 activity by the ribosomal protein L11," Cancer Cell, vol. 3, no. 6, pp. 577-587, 2003.

[93] Y. Zhang, G. W. Wolf, K. Bhat et al., "Ribosomal protein L11 negatively regulates oncoprotein MDM2 and mediates a p53dependent ribosomal-stress checkpoint pathway," Molecular and Cellular Biology, vol. 23, no. 23, pp. 8902-8912, 2003.

[94] K. P. Bhat, K. Itahana, A. Jin, and Y. Zhang, "Essential role of ribosomal protein L11 in mediating growth inhibitioninduced p53 activation," EMBO Journal, vol. 23, no. 12, pp. 2402-2412, 2004.

[95] M. S. Dai, S. X. Zeng, Y. Jin, X. X. Sun, L. David, and H. Lu, "Ribosomal protein L23 activates p53 by inhibiting MDM2 function in response to ribosomal perturbation but not to translation inhibition," Molecular and Cellular Biology, vol. 24, no. 17, pp. 7654-7668, 2004.

[96] Y. Ofir-Rosenfeld, K. Boggs, D. Michael, M. B. Kastan, and $\mathrm{M}$. Oren, "Mdm2 regulates p53 mRNA translation through inhibitory interactions with ribosomal protein L26," Molecular Cell, vol. 32, no. 2, pp. 180-189, 2008.

[97] D. Chen, Z. Zhang, M. Li et al., "Ribosomal protein S7 as a novel modulator of p53-MDM2 interaction: binding to MDM2, stabilization of $\mathrm{p} 53$ protein, and activation of $\mathrm{p} 53$ function," Oncogene, vol. 26, no. 35, pp. 5029-5037, 2007.

[98] Y. Zhang and H. Lu, "Signaling to p53: ribosomal proteins find their way," Cancer Cell, vol. 16, no. 5, pp. 369-377, 2009.

[99] Y. Zhang, J. Wang, Y. Yuan et al., "Negative regulation of HDM2 to attenuate p53 degradation by ribosomal protein L26," Nucleic Acids Research, vol. 38, no. 19, Article ID gkq536, pp. 6544-6554, 2010.

[100] D. G. Pestov, Z. Strezoska, and L. F. Lau, "Evidence of p53dependent cross-talk between ribosome biogenesis and the cell cycle: effects of nucleolar protein Bop1 on G1/S transition," Molecular and Cellular Biology, vol. 21, no. 13, pp. 4246-4255, 2001.

[101] C. Deisenroth and Y. Zhang, "Ribosome biogenesis surveillance: probing the ribosomal protein-Mdm2-p53 pathway," Oncogene, vol. 29, no. 30, pp. 4253-4260, 2010.

[102] D. M. Gilkes, L. Chen, and J. Chen, "MDMX regulation of p53 response to ribosomal stress," EMBO Journal, vol. 25, no. 23, pp. 5614-5625, 2006.

[103] X. X. Sun, Y. G. Wang, D. P. Xirodimas, and M. S. Dai, "Perturbation of $60 \mathrm{~S}$ ribosomal biogenesis results in ribosomal protein L5- and L11-dependent p53 activation," Journal of Biological Chemistry, vol. 285, no. 33, pp. 25812-25821, 2010.

[104] A. Pellagatti, T. Marafioti, J. C. Paterson et al., "Induction of p53 and up-regulation of the p53 pathway in the human 5qsyndrome," Blood, vol. 115, no. 13, pp. 2721-2723, 2010. 
[105] M. E. Perry, "The regulation of the p53-mediated stress response by MDM2 and MDM4," Cold Spring Harbor Perspectives in Biology, vol. 2, no. 1, article a000968, 2010.

[106] J. S. L. Ho, W. Ma, D. Y. L. Mao, and S. Benchimol, "p53dependent transcriptional repression of c-myc is required for G 1 cell cycle arrest," Molecular and Cellular Biology, vol. 25, no. 17, pp. 7423-7431, 2005.

[107] M. Sachdeva, S. Zhu, F. Wu et al., "p53 represses c-Myc through induction of the tumor suppressor miR-145," Proceedings of the National Academy of Sciences of the United States of America, vol. 106, no. 9, pp. 3207-3212, 2009.

[108] M. Sachdeva and Y. Y. Mo, "p53 and c-myc: how does the cell balance "yin" and "yang"?" Cell Cycle, vol. 8, no. 9, p. 1303, 2009.

[109] A. H. L. Truong, D. Cervi, J. Lee, and Y. Ben-David, "Direct transcriptional regulation of MDM2 by Fli-1," Oncogene, vol. 24, no. 6, pp. 962-969, 2005.

[110] D. H. Christiansen, M. K. Andersen, and J. Pedersen-Bjergaard, "Mutations with loss of heterozygosity of p53 are common in therapy-related myelodysplasia and acute myeloid leukemia after exposure to alkylating agents and significantly associated with deletion or loss of $5 \mathrm{q}$, a complex karyotype, and a poor prognosis," Journal of Clinical Oncology, vol. 19, no. 5, pp. 1405-1413, 2001.

[111] J. Pedersen-Bjergaard, M. K. Andersen, M. T. Andersen, and D. H. Christiansen, "Genetics of therapy-related myelodysplasia and acute myeloid leukemia," Leukemia, vol. 22, no. 2, pp. 240-248, 2008.

[112] M. Jädersten, L. Saft, A. Pellagatti et al., "Clonal heterogeneity in the 5q- syndrome: P53 expressing progenitors prevail during lenalidomide treatment and expand at disease progression," Haematologica, vol. 94, no. 12, pp. 1762-1766, 2009.

[113] M. Jädersten, L. Saft, A. Smith et al., “TP53 mutations in lowrisk myelodysplastic syndromes with $\operatorname{del}(5 \mathrm{q})$ predict dinase progression," Journal of Clinical Oncology, vol. 29, pp. 19711979, 2011.

[114] C. M. Lim, M. A. Cater, J. F. B. Mercer, and S. La Fontaine, "Copper-dependent interaction of dynactin subunit p62 with the N terminus of ATP7B but not ATP7A," Journal of Biological Chemistry, vol. 281, no. 20, pp. 14006-14014, 2006.

[115] S. R. Patel, J. L. Richardson, H. Schulze et al., "Differential roles of microtubule assembly and sliding in proplatelet formation by megakaryocytes," Blood, vol. 106, no. 13, pp. 4076-4085, 2005.

[116] J. E. Italiano Jr., S. Patel-Hett, and J. H. Hartwig, "Mechanics of proplatelet elaboration," Journal of Thrombosis and Haemostasis, vol. 5, supplement 1, pp. 18-23, 2007.

[117] F. He, C. T. Wang, and L. T. Gou, "RNA-binding motif protein RBM22 is required for normal development of zebrafish embryos," Genetics and Molecular Research, vol. 8, no. 4, pp. 1466-1473, 2009.

[118] S. Grisendi, R. Bernardi, M. Rossi et al., "Role of nucleophosmin in embryonic development and tumorigenesis," Nature, vol. 437, no. 7055, pp. 147-153, 2005.

[119] S. Grisendi, C. Mecucci, B. Falini, and P. P. Pandolfi, "Nucleophosmin and cancer," Nature Reviews Cancer, vol. 6, no. 7, pp. 493-505, 2006.

[120] P. Sportoletti, S. Grisendi, S. M. Majid et al., "Npm1 is a haploinsufficient suppressor of myeloid and lymphoid malignancies in the mouse," Blood, vol. 111, no. 7, pp. 3859-3862, 2008 .
[121] G. Cazzaniga, M. G. Dell'Oro, C. Mecucci et al., "Nucleophosmin mutations in childhood acute myelogenous leukemia with normal karyotype," Blood, vol. 106, no. 4, pp. 14191422, 2005.

[122] R. Rau and P. Brown, "Nucleophosmin (NPM1) mutations in adult and childhood acute myeloid leukaemia: towards definition of a new leukaemia entity," Hematological Oncology, vol. 27, no. 4, pp. 171-181, 2009.

[123] M. J. Walter, "Del(5q): gene dosage matters," Blood, vol. 110, no. 2, pp. 473-474, 2007.

[124] R. Neuwirtova, O. Fuchs, D. Provaznikova et al., "Fli-1 and EKLF gene expression in patients with MDS 5q- syndrome," Blood, vol. 114, pp. 1090-1091, 2009, abstract no. 2788, Proceedings of the 51st Annual Meeting of the American Society of Hematology, December 5-8, 2009, New Orleans, La, USA.

[125] R. Neuwirtova, O. Fuchs, A. Jonasova et al., "The role of Fli-1 and EKLF gene expression in 5q- syndrome compared to MDS low risk with normal chromosome 5," in Proceedings of the XXXIII World Congress of the International Society of Hematology, Jerusalem, Israel, abstract no. 114, October 2010.

[126] Y. Ben-David, E. B. Giddens, K. Letwin, and A. Bernstein, "Erythroleukemia induction by Friend murine leukemia virus: insertional activation of a new member of the ets gene family, Fli-1, closely linked to c-ets-1," Genes and Development, vol. 5, no. 6, pp. 908-918, 1991.

[127] D. K. Watson, F. E. Smyth, D. M. Thompson et al., "The ERGB/Fli-1 gene: isolation and characterization of a new member of the family of human ETS transcription factors," Cell Growth and Differentiation, vol. 3, no. 10, pp. 705-713, 1992.

[128] D. D. K. Prasad, V. N. Rao, and E. S. P. Reddy, "Structure and expression of human Fli-1 gene," Cancer Research, vol. 52, no. 20, pp. 5833-5837, 1992.

[129] L. Selleri, M. Giovannini, A. Romo et al., "Cloning of the entire FLI1 gene, disrupted by the Ewing's sarcoma translocation breakpoint on 11q24, in a yeast artificial chromosome," Cytogenetics and Cell Genetics, vol. 67, no. 2, pp. 129-136, 1994.

[130] J. Starck, N. Cohet, C. Gonnet et al., "Functional crossantagonism between transcription factors FLI-1 and EKLF," Molecular and Cellular Biology, vol. 23, no. 4, pp. 1390-1402, 2003.

[131] M. Eisbacher, M. L. Holmes, A. Newton et al., "Proteinprotein interaction between Fli-1 and GATA-1 mediates synergistic expression of megakaryocyte-specific genes through cooperative DNA binding," Molecular and Cellular Biology, vol. 23, no. 10, pp. 3427-3441, 2003.

[132] P. Jackers, G. Szalai, O. Moussa, and D. K. Watson, "Etsdependent regulation of target gene expression during megakaryopoiesis," Journal of Biological Chemistry, vol. 279, no. 50, pp. 52183-52190, 2004.

[133] J. L. Svenson, K. Chike-Harris, M. Y. Amria, and T. K. Nowling, "The mouse and human Flil genes are similarly regulated by Ets factors in T cells," Genes and Immunity, vol. 11, no. 2, pp. 161-172, 2010.

[134] J. Starck, A. Doubeikovski, S. Sarrazin et al., "Spi-1/PU.1 Is a positive regulator of the Fli-1 gene involved in inhibition of erythroid differentiation in friend erythroleukemic cell lines," Molecular and Cellular Biology, vol. 19, no. 1, pp. 121-135, 1999. 
[135] N. Rekhtman, F. Radparvar, T. Evans, and A. I. Skoultchi, "Direct interaction of hematopoietic transcription factors PU.1 and GATA- 1: functional antagonism in erythroid cells," Genes and Development, vol. 13, no. 11, pp. 1398-1411, 1999.

[136] P. Zhang, X. Zhang, A. Iwama et al., "PU.1 inhibits GATA-1 function and erythroid differentiation by blocking GATA-1 DNA binding," Blood, vol. 96, no. 8, pp. 2641-2648, 2000.

[137] G. Juban, G. Giraud, B. Guyot et al., "Spi-1 and Fli-1 directly activate common target genes involved in ribosome biogenesis in friend erythroleukemic cells," Molecular and Cellular Biology, vol. 29, no. 10, pp. 2852-2864, 2009.

[138] D. T. Starczynowski and A. Karsan, "Innate immune signaling in the myelodysplastic syndromes," Hematology/Oncology Clinics of North America, vol. 24, pp. 343-359, 2010.

[139] D. R. Hodge, W. Xiao, P. A. Clausen, G. Heidecker, M. Szyf, and W. L. Farrar, "Interleukin-6 regulation of the human DNA methyltransferase (HDNMT) gene in human erythroleukemia cells," Journal of Biological Chemistry, vol. 276, no. 43, pp. 39508-39511, 2001.

[140] D. R. Hodge, D. Li, S. M. Qi, and W. L. Farrar, "IL-6 induces expression of the Fli-1 proto-oncogene via STAT3," Biochemical and Biophysical Research Communications, vol. 292, pp. 287-291, 2002.

[141] M. R. Tallack, T. Whitington, W. S. Yuen et al., "A global role for KLF1 in erythropoiesis revealed by ChIP-seq in primary erythroid cells," Genome Research, vol. 20, no. 8, pp. 10521063, 2010.

[142] M. Siatecka and J. J. Bieker, "The multifunctional role of EKLF/KLF1 during erythropoiesis," Blood, vol. 118, pp. 2044-2054, 2011.

[143] L. C. Doré and J. D. Crispino, "Transcription factor in erythroid cell and megakaryocyte development," Blood, vol. 118, pp. 231-239, 2011.

[144] J. Borg, P. Papadopoulos, M. Georgitsi et al., "Haploinsufficiency for the erythroid transcription factor KLF1 causes hereditary persistence of fetal hemoglobin," Nature Genetics, vol. 42, no. 9, pp. 801-805, 2010.

[145] P. Frontelo, D. Manwani, M. Galdass et al., "Novel role for EKLF in megakaryocyte lineage commitment," Blood, vol. 110, no. 12, pp. 3871-3880, 2007.

[146] F. Bouilloux, G. Juban, N. Cohet et al., "EKLF restricts megakaryocytic differentiation at the benefit of erythrocytic differentiation," Blood, vol. 112, no. 3, pp. 576-584, 2008.

[147] O. Klimchenko, M. Mori, A. DiStefano et al., "A common bipotent progenitor generates the erythroid and megakaryocyte lineages in embryonic stem cell-derived primitive hematopoiesis," Blood, vol. 114, no. 8, pp. 1506-1517, 2009.

[148] M. R. Tallack and A. C. Perkins, "Megakaryocyte-erythroid lineage promiscuity in EKLF null mouse blood," Haematologica, vol. 95, no. 1, pp. 144-147, 2010.

[149] S. Dutt, A. Narla, K. Lin et al., "Haploinsufficiency for ribosomal protein genes causes selective activation of p53 in human erythroid progenitor cells," Blood, vol. 117, no. 9, pp. 2567-2576, 2011.

[150] M. Cazzola, "Myelodysplastic syndrome with isolated 5q deletion (5q- syndrome). A clonal stem cell disorder characterized by defective ribosome biogenesis," Haematologica, vol. 93, no. 7, pp. 967-972, 2008.

[151] J. L. Barlow, L. F. Drynan, N. L. Trim, W. N. Erber, A. J. Warren, and A. N. J. McKenzie, "New insights into 5qsyndrome as a ribosomopathy," Cell Cycle, vol. 9, no. 21, pp. 4286-4293, 2010.
[152] Y. Liu, S. E. Elf, Y. Miyata et al., "p53 regulates hematopoietic stem cell quiescence," Cell Stem Cell, vol. 4, no. 1, pp. 37-48, 2009.

[153] Y. Liu, S. E. Elf, T. Asai et al., "The p53 tumor suppressor protein is a critical regulator of hematopoietic stem cell behavior," Cell Cycle, vol. 8, no. 19, pp. 3120-3124, 2009.

[154] E. Wattel, C. Preudhomme, B. Hecquet et al., "p53 Mutations are associated with resistance to chemotherapy and short survival in hematologic malignancies," Blood, vol. 84, no. 9, pp. 3148-3157, 1994.

[155] Y. Kita-Sasai, S. Horiike, S. Misawa et al., "International prognostic scoring system and TP53 mutations are independent prognostic indicators for patients with myelodysplastic syndrome," British Journal of Haematology, vol. 115, no. 2, pp. 309-312, 2001.

[156] S. Horiike, Y. Kita-Sasai, M. Nakao, and M. Taniwaki, "Configuration of the TP53 gene as an independent prognostic parameter of myelodysplastic syndrome," Leukemia and Lymphoma, vol. 44, no. 6, pp. 915-922, 2003.

[157] L. Garderet, L. Kobari, C. Mazurier et al., "Unimpaired terminal erythroid differentiation and preserved enucleation capacity in myelodysplastic $5 \mathrm{q}(\mathrm{del})$ clones: a single cell study," Haematologica, vol. 95, no. 3, pp. 398-405, 2010.

[158] T. M. A. Neildez-Nguyen, H. Wajcman, M. C. Marden et al., "Human erythroid cells produced ex vivo at large scale differentiate into red blood cells in vivo," Nature Biotechnology, vol. 20, no. 5, pp. 467-472, 2002.

[159] M. C. Giarratana, L. Kobari, H. Lapillonne et al., "Ex vivo generation of fully mature human red blood cells from hematopoietic stem cells," Nature Biotechnology, vol. 23, no. 1, pp. 69-74, 2005.

[160] M. Jädersten, "Pathophysiology and treatment of the myelodysplastic syndrome with isolated 5q deletion," Haematologica, vol. 95, no. 3, pp. 348-351, 2010.

[161] M. Virgilio, E. Payne, A. Narla et al., "Treatment of zebrafish models of ribosomopathies (Diamond Blackfan anemia (DBA) and 5q-syndrome with Lleucine results in an improvement of anemia and development defects: evidence for a common pathway," Blood, vol. 116, abstract 195, pp. 8990, 2010.

[162] J. Cmejlova, L. Dolezalova, D. Pospisilova, K. Petrtylova, J. Petrak, and R. Cmejla, "Translational efficiency in patients with Diamond-Blackfan anemia," Haematologica, vol. 91, no. 11, pp. 1456-1464, 2006.

[163] J. C. Anthony, T. G. Anthony, S. R. Kimball, T. C. Vary, and L. S. Jefferson, "Orally administered leucine stimulates protein synthesis in skeletal muscle of postabsorptive rats in association with increased elF4F formation," Journal of Nutrition, vol. 130, no. 2, pp. 139-145, 2000.

[164] C. J. Lynch, B. J. Patson, J. Anthony et al., "Leucine is a direct-acting nutrient signal that regulates protein synthesis in adipose tissue," American Journal of Physiology, vol. 283, pp. E506-E513, 2002.

[165] L. E. Norton and D. K. Layman, "Leucine regulates translation initiation of protein synthesis in skeletal muscle after excercise," Journal of Nutrition, vol. 136, pp. 533S-537S, 2006.

[166] J. Escobar, J. W. Frank, A. Suryawan et al., "Amino acid availability and age affect the leucine stimulation of protein synthesis and eIF4F formation in muscle," American Journal of Physiology, vol. 293, pp. E1615-E1621, 2007.

[167] D. Pospisilova, J. Cmejlova, J. Hak, T. Adam, and R. Cmejla, "Successful treatment of a Diamond-Blackfan anemia patient with amino acid leucine," Haematologica, vol. 92, no. 5, pp. e66-67, 2007. 
[168] A. List, G. Dewald, J. Bennett et al., "Lenalidomide in the myelodysplastic syndrome with chromosome 5q deletion," The New England Journal of Medicine, vol. 355, no. 14, pp. 1456-1465, 2006.

[169] M. Melchert, V. Kale, and A. List, "The role of lenalidomide in the treatment of patients with chromosome $5 \mathrm{q}$ deletion and other myelodysplastic syndromes," Current Opinion in Hematology, vol. 14, no. 2, pp. 123-129, 2007.

[170] A. F. List, "Lenalidomide-the phoenix rises," The New England Journal of Medicine, vol. 357, no. 21, pp. 2183-2186, 2007.

[171] S. Kurtin and A. List, "Durable long-term responses in patients with myelodysplastic syndromes treated with lenalidomide," Clinical Lymphoma and Myeloma, vol. 9, no. 3, pp. E10-E13, 2009.

[172] R. S. Komrojki and A. F. List, "Lenalidomide for teatment of myelodysplastic syndromes: current status and future directions," Hematology/Oncology Clinics of North America, vol. 24, pp. 377-388, 2010.

[173] S. M. Post and A. Quintás-Cardama, "Closing in on the pathogenesis of the 5q- syndrome," Expert Review of Anticancer Therapy, vol. 10, no. 5, pp. 655-658, 2010.

[174] A. Raza, J. A. Reeves, E. J. Feldman et al., "Phase 2 study of lenalidomide in transfusion-dependent, low-risk, and intermediate-1-risk myelodysplastic syndromes with karyotypes other than deletion 5q," Blood, vol. 111, no. 1, pp. 8693, 2008 .

[175] B. L. Ebert, N. Galili, P. Tamayo et al., "An erythroid differentiation signature predicts response to lenalidomide in myelodysplastic syndrome," PLoS Medicine, vol. 5, no. 2, pp. 0312-0322, 2008.

[176] C. Chen, D. T. Bowen, A. A. N. Giagounidis, B. Schlegelberger, S. Haase, and E. G. Wright, "Identification of disease- and therapy-associated proteome changes in the sera of patients with myelodysplastic syndromes and del(5q)," Leukemia, vol. 24, no. 11, pp. 1875-1884, 2010.

[177] S. Wei, X. Chen, K. Rocha et al., "A critical role for phosphatase haplodeficiency in the selective suppression of deletion 5q MDS by lenalidomide," Proceedings of the National Academy of Sciences of the United States of America, vol. 106, no. 31, pp. 12974-12979, 2009.

[178] S. H. Kimura and H. Nojima, "Cyclin G1 associates with MDM2 and regulates accumulation and degradation of p53 protein," Genes to Cells, vol. 7, no. 8, pp. 869-880, 2002.

[179] X. K. Zhang and D. K. Watson, "The FLI-1 transcription factor is a short-lived phosphoprotein in T cells," Journal of Biochemistry, vol. 137, no. 3, pp. 297-302, 2005.

[180] J. B. Bartlett, K. Dredge, and A. G. Dalgleish, "The evolution of thalidomide and its IMiD derivatives as anticancer agents," Nature Reviews Cancer, vol. 4, no. 4, pp. 314-322, 2004.

[181] A. Pellagatti, M. Jädersten, A. M. Forsblom et al., "Lenalidomide inhibits the malignant clone and up-regulates the SPARC gene mapping to the commonly deleted region in 5qsyndrome patients," Proceedings of the National Academy of Sciences of the United States of America, vol. 104, no. 27, pp. 11406-11411, 2007.

[182] E. N. Oliva, M. Cuzzola, F. Nobile et al., "Changes in RPS14 expression levels during lenalidomide treatment in Low- and Intermediate-1-risk myelodysplastic syndromes with chromosome 5q deletion," European Journal of Haematology, vol. 85, no. 3, pp. 231-235, 2010.

[183] C. P. Venner, A. F. List, T. J. Nevill et al., "Induction of micro RNA-143 and 145 in pre-treatment CD34+ cells from patients with myelodysplastic syndrome (MDS) after in vitro exposure to lenalidomide correlates with clinical response in patients harboring the del5q abnormality," Blood, vol. 116, abstract 123, p. 60, 2010.

[184] M. Ximeri, A. Galanopoulos, M. Klaus et al., "Effect of lenalidomide therapy on hematopoiesis of patients with myelodysplastic syndrome associated with chromosome $5 \mathrm{q}$ deletion," Haematologica, vol. 95, no. 3, pp. 406-414, 2010.

[185] R. Tehranchi, P. S. Woll, K. Anderson et al., "Persistent malignant stem cells in del $(5 q)$ myelodysplasia in remission," The New England Journal of Medicine, vol. 363, no. 11, pp. 10251037,2010 


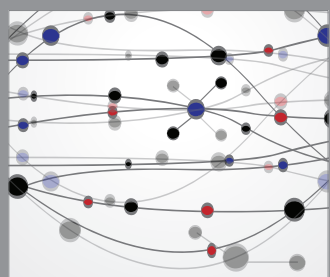

The Scientific World Journal
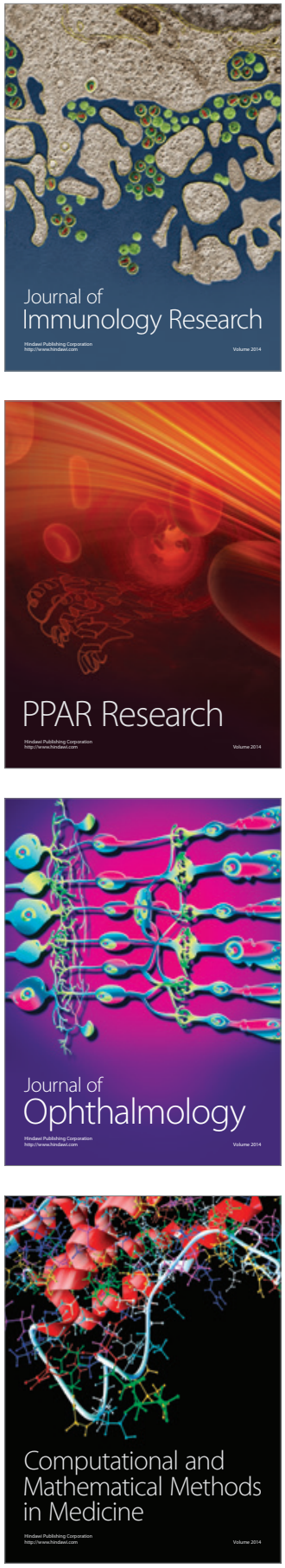

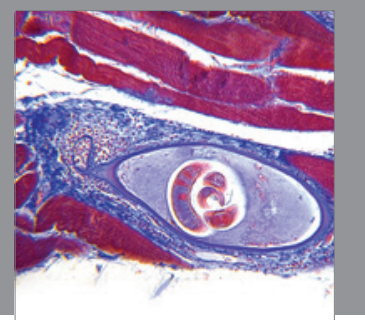

Gastroenterology

Research and Practice
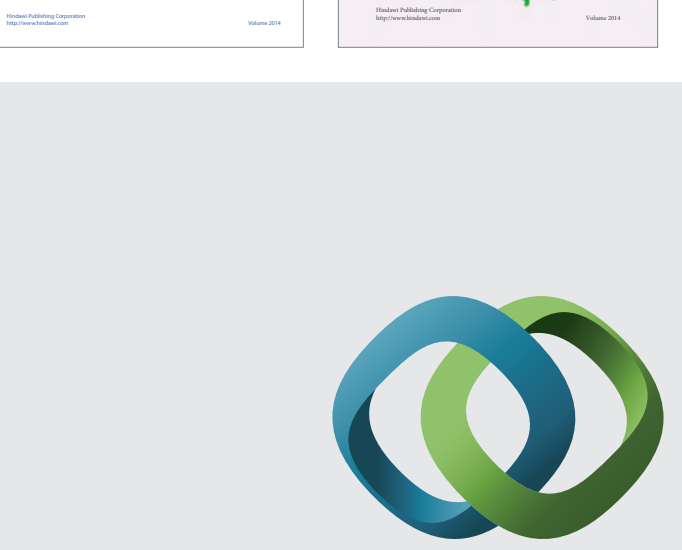

\section{Hindawi}

Submit your manuscripts at

http://www.hindawi.com
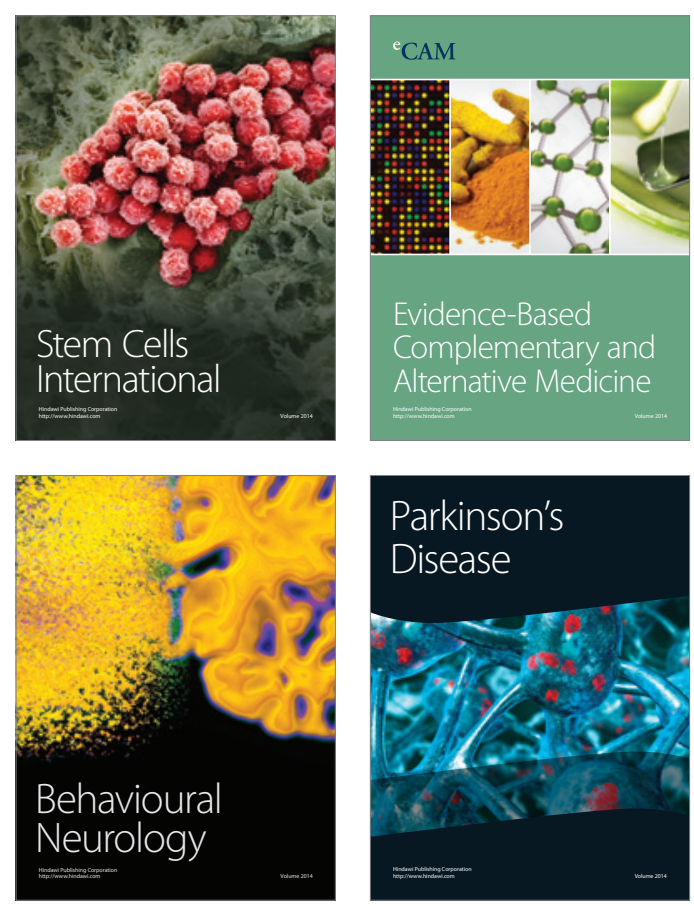

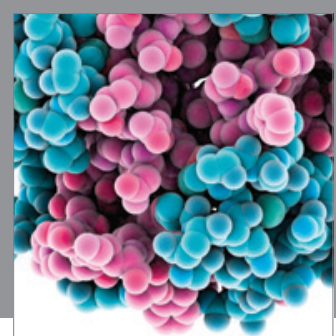

Journal of
Diabetes Research

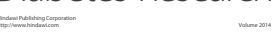

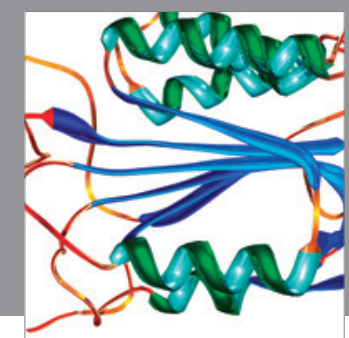

Disease Markers
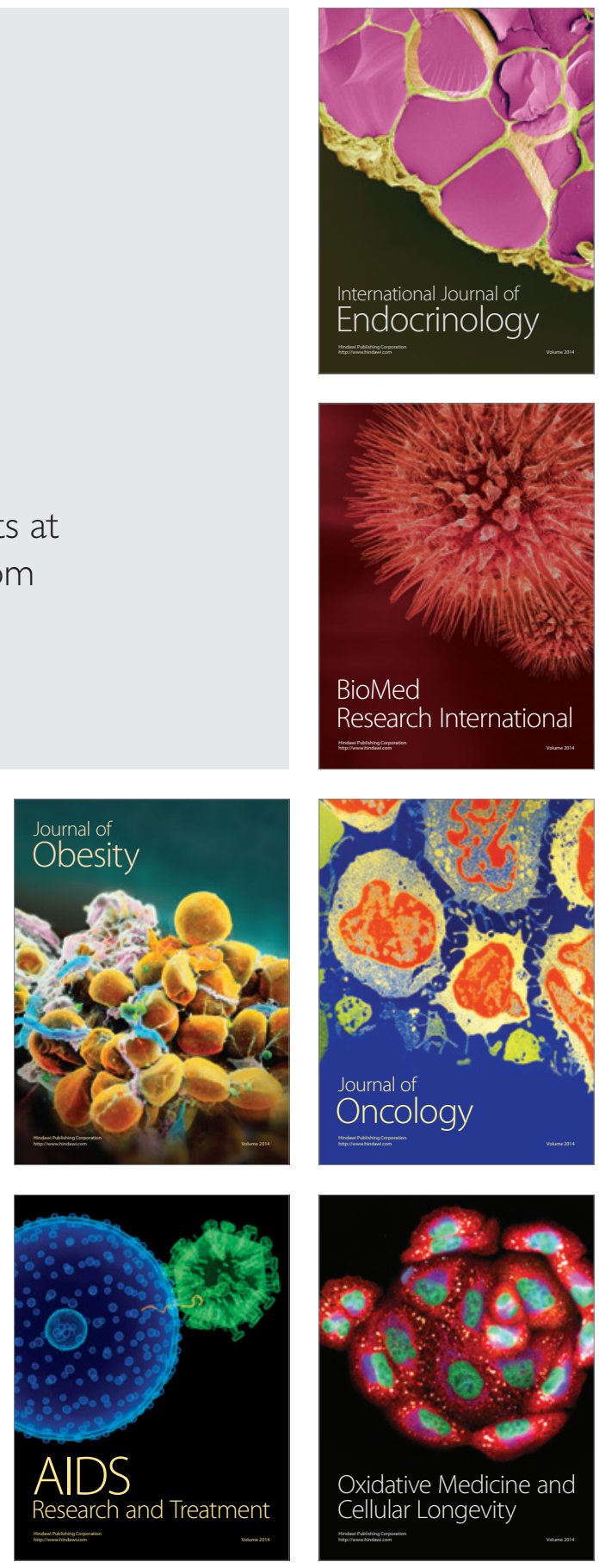